\title{
Correction to: Healthcare wearable devices: an analysis of key factors for continuous use intention
}

\author{
Sang M. Lee ${ }^{1} \cdot$ DonHee Lee ${ }^{2}$
}

Published online: 30 October 2020

๑) Springer-Verlag GmbH Germany, part of Springer Nature 2020

\section{Correction to: Service Business https://doi.org/10.1007/s11628-020-00428-3}

This correction is published as the acknowledgement "This work was supported by INHA UNIVERSITY Research Grant." was not included in original publication.

Publisher's Note Springer Nature remains neutral with regard to jurisdictional claims in published maps and institutional affiliations.

The original article can be found online at https://doi.org/10.1007/s11628-020-00428-3.

\section{DonHee Lee}

dhlee04@inha.ac.kr

Sang M. Lee

slee1@unl.edu

1 College of Business, University of Nebraska-Lincoln, Lincoln, NE, USA

2 College of Business Administration, Inha University, 100 Inharo, Michuhol-gu, Incheon, South Korea 